Adv. Geosci., 10, 59-66, 2007

www.adv-geosci.net/10/59/2007/

(C) Author(s) 2007. This work is licensed

under a Creative Commons License.

\title{
On extreme daily precipitation totals at Athens, Greece
}

\author{
P. T. Nastos and C. S. Zerefos \\ Laboratory of Climatology and Atmospheric Environment, Faculty of Geology and Geoenvironment, National and \\ Kapodistrian University of Athens, Greece
}

Received: 11 July 2006 - Revised: 9 December 2006 - Accepted: 16 January 2007 - Published: 26 April 2007

\begin{abstract}
The paper studies changes in daily precipitation records at the National Observatory, Athens, during the period 1891-2004. This is the longest available time series of precipitation for Greece. The results show that both the shape and scale parameter of a fitted two parameter gamma distribution for the last two decades do show a significant difference of these parameters, when compared to any previous period from the 1890s through the 1970s. Also important changes are observed in daily precipitation totals exceeding various thresholds such as $10,20,30$ and $50 \mathrm{~mm}$. More specifically, a negative trend in the number of wet days (remarkable after 1968) and a positive trend in extreme daily precipitation are evident. The changes of heavy and extreme precipitation events in this part of SE Europe have significant environmental consequences which cause considerable damage and loss of life.
\end{abstract}

\section{Introduction}

Significant climatic changes of precipitation in the 20th century reflect in economic, social and ecological implications including droughts, frequency of intense precipitation and of wet days (Karl and Knight, 1998; Folland and Karl, 2001; Zhang et al., 2001). For Europe, the precipitation trend is positive in the north (Forland et al., 1996; Schonwiese and Rapp, 1997) and negative in the south (Schonwiese and Rapp, 1997). Anagnostopoulou et al. (2006) studying the cyclones in the Mediterranean region, found that the Hadley Center atmospheric General Circulation Model (HadAM3P) predicts a future decrease of the frequency of the severe cyclones $(<1000 \mathrm{hPa})$ at the SLP level, but the future cyclones will be more intense, especially at the $500 \mathrm{hPa}$ level.

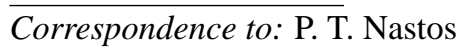

(nastos@geol.uoa.gr)
Studies regarding long precipitation timeseries and the distribution of precipitation frequency within the Mediterranean Sea and Greece have been carried out by many researchers (Zerefos et al., 1977; Maheras, 1981; Repapis, 1986; Katsoulis and Kambezidis, 1989; Maheras and Kolyva-Mahera, 1990; Flocas et al., 1990; Amanatidis et al., 1993; Nastos, 1993; Mantis et al., 1994; Amanatidis et al., 1997; Metaxas et al., 1999; Brunetti et al., 2001).

The variability of the total precipitation can be explained by a change in the frequency of precipitation events, or in the intensity of precipitation, or both. In contrast with the simulations of extreme temperature by climate models, extreme precipitation is difficult to reproduce, especially for the intensities and patterns of heavy rainfall which are heavily affected by the local scale (IPCC 2001). For this reason, it is necessary to study heavy and extreme precipitation events by analyzing long time series of observed station data.

In this study, we examine the long time series of daily precipitation recorded in the National Observatory of Athens (NOA), for the period 1891-2004, by fitting the gamma distribution to the datasets per decade and by manipulating the exceedances of the daily precipitation over various thresholds, which are indicators for the incidence of extreme rainfall events responsible for social and economical consequences.

\section{Data and analysis}

Daily precipitation dataset recorded at the meteorological station of the National Observatory of Athens (Longitude: $23^{\circ} 43 \mathrm{E}$, Latitude: $37^{\circ} 58 \mathrm{~N}$, Altitude: $107 \mathrm{~m}$ a.m.s.l.), for the period 1891-2004, was analyzed in this study. This is the longest available and reliable time series of precipitation for Greece. Even in reliable precipitation datasets there is a measurement uncertainty, because of errors due to gauge undercatch mostly depending on wind characteristics during

Published by Copernicus GmbH on behalf of the European Geosciences Union. 
Table 1. Parameters of the gamma distribution fitted to daily precipitation data over ten year periods for NOA.

\begin{tabular}{ccccc}
\hline Period & Observed Mean & Observed Variance & Scale Parameter & ShapeParameter \\
\hline $1891-1900$ & 5.12 & 126.03 & 7.82 & 0.66 \\
$1901-1910$ & 6.31 & 72.76 & 8.65 & 0.73 \\
$1911-1920$ & 6.45 & 98.62 & 9.49 & 0.68 \\
$1921-1930$ & 6.35 & 97.89 & 9.69 & 0.66 \\
$1931-1940$ & 6.36 & 78.04 & 9.58 & 0.66 \\
$1941-1950$ & 5.83 & 95.75 & 8.96 & 0.65 \\
$1951-1960$ & 5.81 & 73.10 & 8.73 & 0.66 \\
$1961-1970$ & 5.67 & 65.80 & 8.18 & 0.69 \\
$1971-1980$ & 6.20 & 89.16 & 9.36 & 0.66 \\
$1981-1990$ & 5.99 & 79.91 & 8.69 & 0.69 \\
$1991-2000$ & 6.62 & 125.19 & 11.40 & 0.58 \\
$2001-2004$ & 9.09 & 227.41 & 16.56 & 0.55 \\
\hline
\end{tabular}

stormy weather (wind-induced turbulence over the orifice of the gauge) and less on evaporation from the gauge.

The first step of the analysis was to divide the dataset in 10-year groups and fit the gamma distribution on each of the 11 daily precipitation timeseries $(1891-1900, \ldots, 1991-$ 2000) in order to find out the change of the distribution parameters extracted. Furthermore, this analysis was applied to the data in 30-year groups. The gamma distribution, which in addition is recommended by the World Meteorological Organization (Thom, 1971; Neyers, 1990), is the most appropriate for studies relative to precipitation distributions due to its moderately skewed profile (Thom, 1958; Ding, 1992; Guttman et al., 1993; Wilks, 1995; Groisman et al., 1999). This distribution has been used for the study of the distribution of the precipitation frequencies in Greece (Katsoulis and Pappas, 2000), as well as for the spatial and temporal analysis of the extreme precipitation in Cyprus (Tymbios and Michailidis, 2002). The benefit of the gamma distribution is the better fitting to the frequency distribution of the precipitation as compared to other theoretical statistical distributions, which either underestimate or overestimate the frequency distribution of the daily precipitation. Furthermore, the increase in the scale parameter $\beta$ (appeared in the formula for the probability density function) results in stretching out the probability density distribution and therefore can be used in the determination of the probability of extreme events. The general formula for the probability density function of the gamma distribution is:

$f(x)=\frac{\left(\frac{x-\mu}{\beta}\right)^{\gamma-1} \exp \left(-\frac{x-\mu}{\beta}\right)}{\beta \Gamma(\gamma)} \quad x \geq \mu, \gamma, \beta>0$

where $\gamma$ is the shape parameter, $\mu$ is the location parameter, $\beta$ is the scale parameter, which characterizes the scale of the intensity of the daily precipitation (the higher $\beta$ is, the higher the intensity is), and $\Gamma$ is the gamma function which has the formula:

$\Gamma(a)=\int_{0}^{\infty} t^{a-1} e^{-t} d t$

The case where $\mu=0$ and $\beta=1$ is called the standard gamma distribution. The equation for the standard gamma distribution reduces to

$f(x)=\frac{x^{\gamma-1} e^{-x}}{\Gamma(\gamma)} \quad x \geq 0 ; \gamma>0$

The second step was to examine the temporal variability and trends of the timeseries of the number of precipitation days exceeding various thresholds such as 10, 20, 30, 40, 50, 60, 70, 80, 90 and $100 \mathrm{~mm}$. Especially the threshold of $50 \mathrm{~mm}$ is considered representative of heavy and extreme rainfalls, by many researchers (Karl et al., 1995; Karl and Knight, 1998; Brunetti et al., 2001, 2004).

\section{Results and discussion}

It has been mentioned previously that the gamma distribution represents daily precipitation satisfactorily. In order to reveal changes in the precipitation variability through time, we constructed the histograms of daily precipitation for 10 year and 30-year periods, along with the gamma distribution, from 1891 to 2004 . The statistics of each 10-year distribution are presented in Table 1 and the respective statistics of each 30-year distribution are presented in Table 2. Although the variance is about the same for 1891-1900 and 1991-2000, the scale parameter is widely different. Regarding the 30year distributions, similar results are extracted indicating a significant differentiation of the statistics for the last period 1981-2004, compared to earlier periods. The increase in the variance and the scale parameter, as well as the shift of the 
Table 2. Parameters of the gamma distribution fitted to daily precipitation data over thirty year periods for NOA.

\begin{tabular}{ccccc}
\hline Period & Observed Mean & Observed Variance & Scale Parameter & Shape Parameter \\
\hline $1891-1920$ & 5.98 & 98.87 & 8.74 & 0.68 \\
$1921-1950$ & 6.19 & 89.89 & 9.42 & 0.66 \\
$1951-1980$ & 5.89 & 75.86 & 8.76 & 0.67 \\
$1981-2004$ & 6.73 & 122.71 & 11.04 & 0.61 \\
\hline
\end{tabular}

mean towards higher values reveal the incidence of extreme daily precipitation values since 1980 s. This is in agreement with the findings of Groisman et al. (1999) who studied the relationship between the increase in total precipitation and the frequency of heavy rain events, over a wide area comprising Canada and Norway (for the period 1900-1995), the USA and Australia (1910-1996), the former Soviet Union (1936-1994), Mexico, China, Alaska and Polland (available data for the post-World War II period). They found that the shape parameter of the precipitation gamma distributions remains rather stable, independent of total precipitation, while the scale parameter is most variable and they also insist that a disproportionate increase in heavy precipitation is expected, as total precipitation increases in the future.

A physical explanation of the enhanced precipitation, mainly in mid-latitude cities, is the urban heat island (UHI). With respect to the National Observatory of Athens (NOA), the urbanization effect is attributed to the extensive building of Athens around NOA after the Second World War and the rapid increase of the population and the number of vehicles mainly after 1970 . The urbanization effect in NOA refers mainly to maximum air temperature (an increase $\sim 2^{\circ} \mathrm{C}$ ) and to the warmer seasons of the year (Philandras et al., 1999). The possible main factors, which cause urban induced changes in precipitation, are the mechanical turbulence resulting from increased surface roughness, the addition of sensible heat from the urban warm air and the anthropogenic condensation nuclei floating in the urban air (Chandler, 1965). These factors are responsible for heavy storms of convective nature in the developed mega-cities. A lot of studies have been carried out providing evidence that UHI is associated with convective precipitation in Atlanta (Bornstein and Lin, 2000), in Mexico city (Jauregui and Romales, 1996), in Tel Aviv (Goldreich and Manes, 1979), in Beijing City (Guo et al., 2006), in Tokyo (Yonetani, 1982) in London (Atkinson, 1971) and in Ankara (Cicek and Turkoglu, 2005).

Moreover, the pronounced increase in heavy precipitation could be attributed to the global warming during the recent decades. Warming relates to higher water content in the atmosphere (Douville et al., 2002; Trenberth et al., 2003) and this has been evident in many regions (Sun et al., 2000; Ross and Elliott, 2001). This phenomenon results in an increase in the probability of severe convective weather.
In the process, a statistical analysis of heavy and extreme events was performed to study their variability and trends. Figure 1 depicts the course of the annual precipitation timeseries (upper graph) and the number of days with precipitation $>0.1 \mathrm{~mm}$ (lower graph), herewith wet days, along with linear and loess fitting.

Annual precipitation has no statistically significant trend ( $p=0.24$ ) in the 1891-2004 period (the peak in the annual timeseries corresponds to the year 2002, and exceeds the average precipitation by over two standard deviations). On the other hand, the wet days series shows a slight negative trend, which is not statistically significant $(p=0.47)$, during the examined period. However, this trend becomes statistically significant $(p=0.03)$ during the last thirty seven years (1968-2004). The absence of a significant trend in annual precipitation and the negative trend in wet days, especially in the last three decades, indicate an increase in the extreme daily precipitation. This temporal pattern is appeared over the northeastern quadrant of the contiguous United States, where during the last 30 years (exactly at the time when most of increase in very heavy precipitation started) a decrease in the number of wet days was observed (Groisman et al., 2005). Additionally, in several regions such as South Africa, Siberia, the Eastern Mediterranean Sea, central Mexico, and northern Japan, rainy days are becoming less frequent and an increase only in heavy precipitation is observed while total precipitation and/or the frequency of days with an appreciable amount of precipitation are not changing and/or are decreasing (Easterling et al., 2000; Alpert et al., 2002; Fauchereau et al., 2003; Groisman et al., 2005). Besides, this is in agreement with the results of Brunetti et al. (2001, 2004), who find a negative significant trend in the number of wet days all over Italy, and a positive trend in precipitation intensity, which is significant only in the northern regions.

In order to verify more systematically the increase in the intensity of the rainfall events, we applied various thresholds $(10 \mathrm{~mm}$ to $100 \mathrm{~mm})$ to daily precipitation timeseries and our findings show a clear increasing trend of the number of days exceeding the examined thresholds, especially $50 \mathrm{~mm}$ (Fig. 2). This is particularly important as these events ( $>50 \mathrm{~mm}$ per day) cause considerable damage and loss of life. 

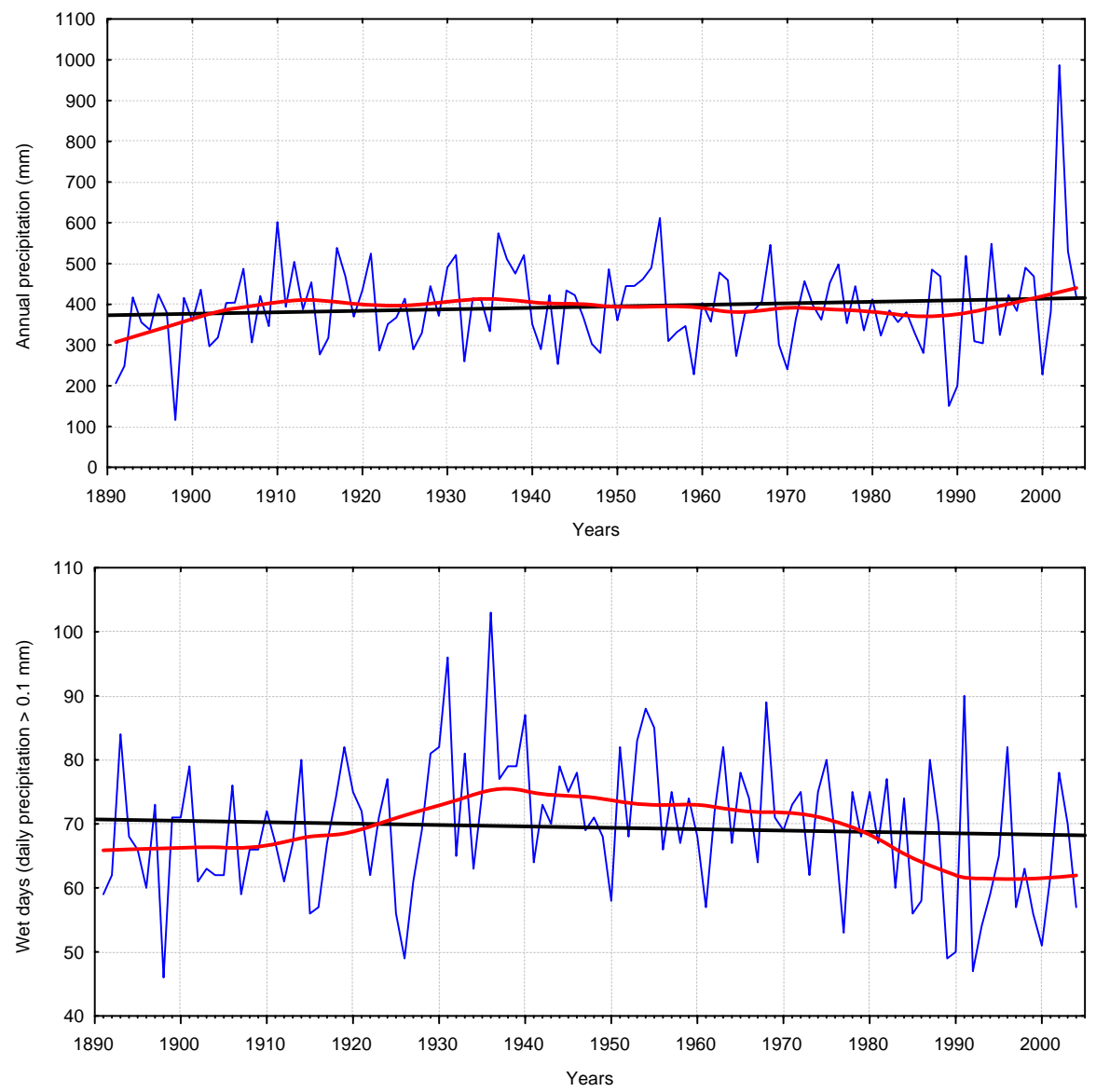

Fig. 1. Time series of annual precipitation (upper graph) and number of days with precipitation $>0.1 \mathrm{~mm}$ (lower graph), along with linear and loess fitting.

More specifically, the increasing trends in the percentages of the number of wet days exceeding specified thresholds are more evident and statistically significant $(p<0.05)$ since the decade of 1970 to present. Figure 2 depicts only the exceedances of the wet days over 10,20,30 and $50 \mathrm{~mm}$ per day, but the same pattern is appeared regarding the thresholds of $60,70,80,90,100 \mathrm{~mm}$, however these events are more infrequent to happen, and their timeseries show a lot of gaps. It should be noted here, the extreme precipitation events during summer-autumn of the year 2002, which are the most intense all over the examined period 1891-2004, causing many disastrous floods and considerable damages all over Greece. Groisman et al. (2005) found out that changes in heavy precipitation frequencies are always higher than changes in precipitation totals and, in some regions, an increase in heavy and/or very heavy precipitation occurred while no change or even a decrease in precipitation totals was observed. Relative studies have been performed for USA by Karl et al. (1995) and Karl and Knight (1998), who remarked a significant positive trend in the frequency of extreme rainfalls (greater than $50 \mathrm{~mm}$ per day) over the last few decades in the USA. Besides, concerning Australia, Suppiah and Hennessy (1998) found a significant increase in the 90th and 95th percentiles of rainfall, while in Japan, Iwashima and Yamamoto (1993) revealed that, the highest precipitation events were recorded in recent decades.

In the process, wavelet analysis (Torrence and Compo, 1998) is used to identify variations in temporal cycles in the annual precipitation in NOA and furthermore to find relationships between annual precipitation and the dominant modes of the climate variability. The wavelet power spectrum and the global wavelet power spectrum are depicted in Fig. 3 . The contour levels are chosen so that $75 \%, 50 \%, 25 \%$, and $5 \%$ of the wavelet power is above each level, respectively. Black contour is the $5 \%$ significance level, using a red-noise (autoregressive lag1) background spectrum. The dashed line is the significance for the global wavelet spectrum, assuming the same significance level and background spectrum as in left graph. Wavelet analysis shows that multidecadal cycles $(\sim 25$ years) are dominated at the beginning and the end of the twentieth century. Moreover 2-10 year period is exhibited at the recent years while $4-8$ year period is appeared at the end of the nineteenth century. 

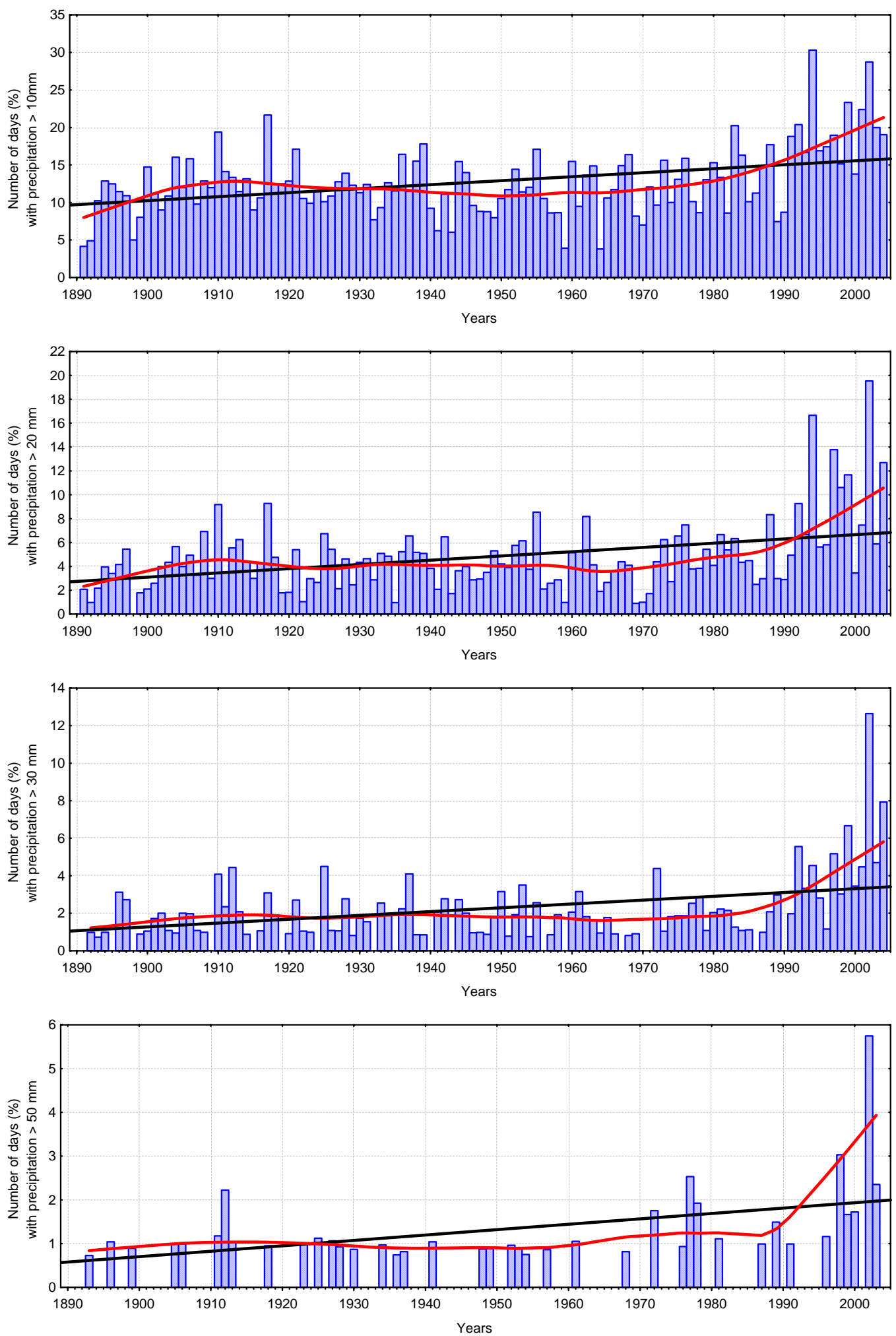

Fig. 2. Time series of the annual percentages of the number of days with precipitation greater than $10 \mathrm{~mm}, 20 \mathrm{~mm}, 30 \mathrm{~mm}$ and $50 \mathrm{~mm}$ (annual number of days exceeding specified thresholds divided by the number of wet days of the year), along with linear and loess fitting. 


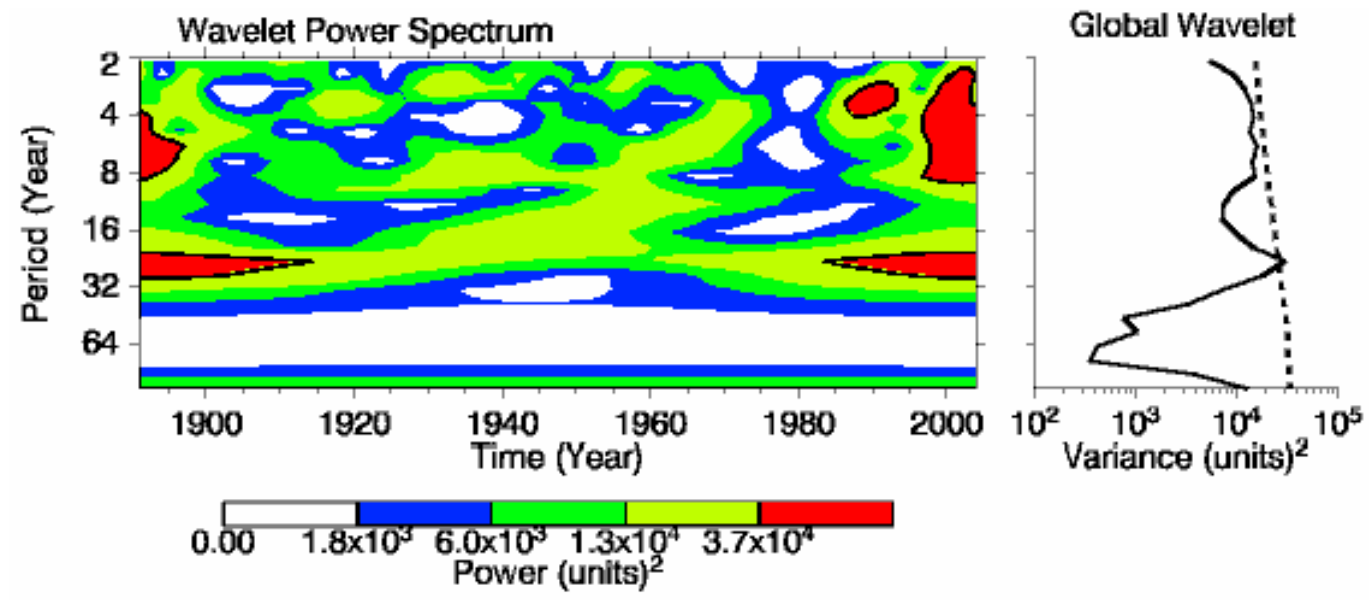

Fig. 3. The wavelet power spectrum (left graph) and the global wavelet power spectrum (right graph).

The quasi biennial and quasi decadal variability could be attributed to North Atlantic Oscillation Index (NAOI) due to conclusions of Hurrell (1995) and Hurrell and Van Loon (1997), who showed that over the past 130 years the NAOI has presented considerable variability at quasi-biennial and quasi-decadal time scales, and the latter have become especially pronounced the second half of this century. Since 1980, NAOI remained in one extreme phase resulting in anomalies in the precipitation, including dry wintertime conditions over southern Europe and the Mediterranean Sea. Xoplaki et al. (2004) studying the influence of large scale dynamics and trends in the wet Mediterranean precipitation variability, found out that inderdecadal change in the first CCA mode (Canonical Correlation Analysis between large scale circulation at different levels and the precipitation) are related to variations in the NAOI and responsible for time scale variations of the Mediterranean precipitation, throughout the twentieth century. Moreover, multidecadal variations characterize the ENSO Euro-Mediterranean relationship during the 20th century (Mariotti et al., 2002).

\section{Conclusions}

The analysis of the daily precipitation timeseries for the $\mathrm{Na}$ tional Observatory of Athens gives the following results:

(i) the increase in the variance and the scale parameter of the fitted gamma distribution, as well as the shift of the mean towards higher values reveal the incidence of extreme daily precipitation values within the last examined fifteen years.

(ii) the annual precipitation timeseries has no statistically significant trend in the 1891-2004 period while the wet days appear a slight negative trend, which is not statistically significant, during the examined period and becomes statistically significant during the last thirty seven years and this drives in more extreme daily precipitation.

(iii) the increasing trends in the percentages of the number of wet days exceeding specified thresholds are more evident and statistically significant since the decade of 1970 to present.

(iv) the wavelet analysis applied to the annual precipitation revealed inter annual, decadal and multidecadal cycles, which dominant modes of variability vary in time.

The information extracted by similar studies of heavy and extreme precipitation events analyzing long timeseries of observed stations datasets will help policy makers, and the community in general, to find ways of protection and limitation of damages by floods and loss of life.

Acknowledgements. Thanks to the unknown reviewers for the constructive comments.

Edited by: S. C. Michaelides and E. Amitai

Reviewed by: anonymous referees

\section{References}

Alpert, P., Ben-Gai, T., Baharad, A., Benjamini, Y., Yekutieli, D., Colacino, M., Diodato, L., Homar, V., Ramis, C., Romero, R., Michaelides, S., and Manes, A.: The paradoxical increase of Mediterranean extreme daily rainfall in spite of decrease in total values, Geophys. Res. Lett., 29(11), 1536, 10.1029/2001GL013554, 2002.

Amanatidis, G. T., Paliatsos, A. G., Repapis, C. C., and Bartzis, J. G.: Decreasing precipitation trend at Marathon area, Greece, Int. J. Climatol., 13, 191-201, 1993.

Amanatidis, G. T., Repapis, C. C., and Paliatsos, A. G.: Precipitation trends and periodicities in Greece, Fresen Environ. Bull., 6, 314-319, 1997. 
Anagnostopoulou, Chr., Tolika, K., Flocas, H., and Maheras, P.: Cyclones in the Mediterranean region: Present and future climate scenarios derived from a general circulation model (HadAM3P), Adv. Geosci., 7, 9-14, 2006, http://www.adv-geosci.net/7/9/2006/.

Atkinson, B. W.: Effect of an urban area on the precipitation from a moving thunderstorm, J. Appl. Meteorol., 10(1), 47-55, 1971.

Bornstein, R. and Lin, Q.: Urban heat islands and summertime convective thunderstorms in Atlanta: three cases studies, Atmos. Environ., 34, 507-516, 2000.

Brunetti, M., Maugeri, M., and Nanni, T.: Changes in total precipitation, rainy days and extreme events in northeastern Italy, Int. J. Climatol., 21, 861-871, 2001.

Brunetti, M., Maugeri, M., Monti, F., and Nanni, T.: Changes in daily precipitation frequency and distribution in Italy over the last 120 years, J. Geophys. Res., 109, D05102, doi:10.1029/2003JD004296, 2004.

Cicek, I. and Turkoglu, N.: Urban effects on precipitation in Ankara, Atmoosfera, 18(3), 173-187, 2005.

Ding, Y. G.: Study of the generality of the Gamma precipitation distribution model, 5th Int. Meeting on Statistical Climatology, June 22-26, Toronto, 499-503, 1992.

Douville, H., Chauvin, F., Planton, S., Royer, J. F., Salas-Melia, D., and Tyteca, S.: Sensitivity of the hydrological cycle to increasing amounts of greenhouse gases and aerosols, Clim. Dyn., 20, 4568, 2002.

Easterling, D. R., Evans, J. L., Groisman, P. Ya., Karl, T. R., Kunkel, K. E., and Ambenje, P.: Observed variability and trends in extreme climate events: A brief review, Bull. Amer. Meteorol. Soc., 81, 417-425, 2000.

Fauchereau, N., Trzaska, S., Rouault, M., and Richard, Y.: Rainfall variavility and changes in Southern Africa during the 20th century in the global warming context, Nat. Hazards, 29, 139-154, 2003.

Flocas, A. A., Bloutsos, A. A., Giles, B. D.: Trends and periodicities of rainfall over Greece, in: Climatic Change in the Historical and the Instrumental Periods, edited by: Brazdil, R., Masaryk University, Brno, Czech Republic, 298-305, 1990.

Folland, C. K. and Karl, T. R.: Observed climate variability and change, pp. 99-181, in: Climate Change 2001: The Scientific Basis, Contribution of Working Group 1 to the Third IPCC Scientific Assessment, edited by: Houghton, J .T., et al., Cambridge University Press, Cambridge, United Kingdom and New York, NY, USA, 881 pp., 2001.

Forland, E. J., van Engelen, A., Aschcroft J., et al.: Change in 'normal' precipitation in the North Atlantic region (2nd edn), DMNI Report 9/96 Klima, 1996.

Goldreich, A. and Manes, Y.: Urban effects of precipitation patterns in the greater Tel-Aviv area, Archiv fur Meteorologie, Geophysik und Bioklimatologie, Serie B, 27(2-3), 213-224, 1979.

Groisman, P. Ya., Karl, T. R., Easterling, D. R., et al.: Changes in the probability of heavy precipitation: Important indicators of climatic change, Clim. Change, 42, 243-283, 1999.

Groisman, P. Ya., Knight, R. W., Easterling, D. R., Karl, T. R., and Hegerl, G. C.: Trends in intense precipitation in the climate record, J. Clim., 18(9), 1326-1350, 2005.

Guo, X., Fu, D., and Wang, J.: Mesoscale convective precipitation system modifiedd by urbanization in Beijing City, Atmos. Res., 82, 112-126, 2006.
Guttman, N. B., Hosking, J. R. M., and Wallis, J. R.: Regional precipitation quantile values for the continental United States computed from L-moments, J. Clim., 6, 2326-2340, 1993.

Hurrell, J. W.: Decadal trends in the North Atlantic Oscilation: Regional temperatures and precipitation, Science, 269(5224), 676679, 1995.

Hurrell, J. W. and Van Loon, H.: Decadal variations in climate associated with the North Atlantic oscillation, Clim. Change, 36, 301-326, 1997.

IPCC, (2001) Climate Change 2001: The Scientific Basis. Contribution of Working Group 1 to the Third IPCC Scientific Assessment, Chapter 8, Model Evaluation.

Iwashima, T. and Yamamoto, R.: A statistical analysis of the extreme events: long-term trend of heavy daily precipitation, J. Meteorol. Soc. Japan, 71, 637-640, 1993.

Jauregui, E. and Romales, E.: Urban effects on convective precipitation in Mexico City, Atmos. Environ., 30(20), 3383-3389, 1996.

Karl, T. R., Knight, R. W., and Plummer, N.: Trends in highfrequency climate variability in the twentieth century, Nature, 377, 217-220, 1995.

Karl, T. R. and Knight, R. W.: Secular trends of precipitation amount frequency and intensity in the United States., Bull. Amer. Meteorol. Soc., 79, 231-241, 1998.

Katsoulis, B. D. and Kambezidis, H. D.: Analysis of the long-term precipitation series at Athens, Greece, Clim. Change, 14, 263290, 1989.

Katsoulis, V. D. and Pappas, C.: Study of the application of the gamma distribution to the frequency distribution of the precipitation, Proceedings of the 5th Hellenic Scientific Congress in Meteorology-Climatology-Atmospheric Physics, Thessaloniki, Greece, 28-30 September 2000, pp. 277-284, 2000.

Maheras, P.: La variabilite des precipitations dans la mer Egee, Archiv Met Geoph Bioklim, Series B, 29, 157-166, 1981.

Maheras, P. and Kolyva-Mahera, F.: Temporal and spatial characteristics of annual precipitation over Balkans in the twentieth century, Int. J. Climatol., 10, 495-504, 1990.

Mantis, H. T., Repapis, C. C., Philandras, C. M., Paliatsos, A. G., and Amanatidis, G. T.: The spatial and temporal structure of the precipitation climate the Eastern Mediterranean; Background for a study of Climate Change, edited by: A. Ghazi, P. Mathy and C. Zerefos, EUR 17 458, Eastern Europe and Global Change, Kassandra, Halkidiki, Greece, 3-10 October 1994, 125-131, 1994.

Mariotti, A., Zeng, N., and Lau, K. M.: Euro-Mediterranean rainfall and ENSO-a seasonally varying relationship, Geophys. Res. Lett., 29(12), 1621, doi:10.1029/2001GL014248, 2002.

Metaxas, D. A., Philandras, C. M., Nastos, P. T., and Repapis, C. C.: Variabiility of precipitation pattern in Greece during the year, Fresen Environ. Bull., 8, 1-6, 1999.

Nastos, P. T.: Changements de la pluviosite en region Hellenique pendant la periode 1858-1992, Proceedings of the 6th Colloque International de Climatologie, 22-25 Septembre 1993, Thessaloniki, Grece, 6, 183-190, 1993.

Neyers, S.: On the statistical analysis of meteorological observations, WMO Techn Note, No. 143, 1990.

Philandras, C. M., Metaxas, D. A., and Nastos, P. T.: Climate variability and urbanization in Athens, Theor. Appl. Climatol., 63(12), 65-72, 1999.

Repapis, C. C.: Temporal fluctuations of precipitation in Greece, Rivista di Meteor Aeron, XLVI, 1-2, 19-25, 1986. 
Ross, R. J. and Elliott, W. P.: Radiosonde-based Northern Hemisphere tropospheric water vapour trends, J. Climate, 14, 16021612, 2001.

Schonwiese, C. D. and Rapp, J.: Climate Trend Atlas of Europe Based on Observations 1891-1990, Kluer Academic Publishers, Dordrecht, 1997.

Sun, B., Groisman, P. Ya., Bradley, R. S., and Keiming, F. T.: Temporal Changes in the Observed Relationship between Cloud Cover and Surface Air Temperature, J. Climate, 13, 4341-4357, 2000.

Suppiah, R. and Hennessy, K. J.: Trends in total rainfall events and number of dry events in Australia, 1910-1990, Int. J. Climatol., 18, 1141-1164, 1998.

Thom, H. C. S.: A note on the gamma distribution, Mon. Wea. Rev., 86, 117-122, 1958.

Thom, H. C. S.: Some methods of climatological analysis, WMO Techn. Note, No. 81, 1971.

Torrence, C. and Compo, G. P.: A Practical Guide to Wavelet Analysis, Bull. Amer. Meteorol. Soc., 79, 61-78, 1998.

Trenberth, K. E., Dai, A., Rasmussen, R. M., and Parsons, D. B.: The changing character of precipitation, Bull. Amer. Meteorol. Soc., 84, 1205-1217, 2003.
Tymbios, F. S. and Michaelides, S. C.: Analysis of the spatial and temporal changes of the precipitation extreme events in Cyprus, Proceedings of the 6th Hellenic Scientific Congress in Meteorology-Climatology-Atmospheric Physics, Janina, Greece, 25-28 September 2002, pp. 476-483, 2002.

Wilks, D. S.: Statistical Methods in the Atmospheric Sciences, Academic Press, San Diego, CA, 1995.

Xoplaki, E., Gonzalez-Rouco, J. F., and Luterbacher, J.: Wet season Mediterranean precipitation variability: influence of large-scale dynamics and trends, Clim. Dyn., 23, 63-78, 2004.

Yonetani, T.: Increase in number of days with heavy precipitation in Tokyo urban area, J. Appl. Meteorol., 21(10), 1466-1471, 1982.

Zerefos, C. S., Kosmas, G. B., Repapis, C. C., and Zambakas, J. D.: Time series analysis of rain at Athens National Observatory during the century 1871-1970, Laboratory of Climatology,University of Athens, Publication No. 14 (in Greek), 1977.

Zhang, X., Hogg, W. D., and Mekis, E.: Spatial and temporal characteristics of heavy precipitation events in Canada, J. Climate, 14, 1923-1936, 2001. 